\title{
Pulmonary manifestations of multicentric Castleman's disease in HIV infection: a clinical, biological and radiological
} study

\author{
A. Guihot**, L-J. Couderc*, F. Agbalika , L. Galicier ${ }^{+}$, P. Bossi”, E. Rivaud*, \\ A. Scherrer ${ }^{\xi}$, D. Zucman ${ }^{f}$, C. Katlama ${ }^{\#}$ and E. Oksenhendler ${ }^{+}$
}

ABSTRACT: The aim of the present study was to report clinical, radiological and bronchoalveolar lavage (BAL) findings in patients with pulmonary manifestations of HIV-associated multicentric Castleman's disease (MCD).

This was a retrospective study of 12 patients with histologically proven MCD.

Clinical manifestations were as follows: dyspnoea (nine out of 12 cases), cough $(n=10)$, bilateral crackles $(n=10)$, together with high fever, malaise, peripheral lymphadenopathy $(n=12)$, and hepatosplenomegaly $(n=10)$. Two patients developed acute respiratory distress syndrome. Chest radiographs and computed tomography scans showed reticular $(n=7)$ and/or nodular $(n=7)$ interstitial patterns, with mediastinal lymphadenopathy $(n=9)$, and bilateral pleural effusion $(n=3)$. Fibreoptic endoscopy was normal in all cases. BAL analysis showed hypercellularity $(n=6)$ and/or lymphocytosis $(n=6)$, and human herpesvirus-8 DNA was detected in two out of two cases. Specific stains and cultures for pathogens were negative. All patients received etoposide and/or vinblastine, and improved after 2-4 days. Relapses were frequent (50 attacks in 12 patients). Six patients developed a non-Hodgkin's lymphoma, and five died.

In conclusion, the pulmonary manifestation of HIV-related multicentric Castleman's disease is an acute reticulo-nodular interstitial pneumonitis, associated with severe systemic symptoms and peripheral lymphadenopathy. In bronchoalveolar lavage fluid, cellularity is not specific and human herpesvirus-8 DNA is detected. The clinical course is specific due to a rapid onset and regression, frequent relapses and a high occurrence of non-Hodgkin's lymphoma.

KEYWORDS: Acute respiratory distress syndrome, HIV, human herpesvirus-8, interstitial pneumonitis, multicentric Castleman's disease, non-Hodgkin's lymphoma

$\mathbf{M}$ ulticentric Castleman's disease (MCD) is a distinct disorder, which is characterised histologically by a marked lymphoproliferation and a follicle-like structure of affected lymphoid tissue [1]. Three histological types are described: hyaline-vascular type, plasma cell type and mixed type [2]. The localised form usually presents as a mediastinal mass, and is cured by surgical resection. MCD is observed in HIV-negative elderly patients [2], but is more frequent in HIV-infected patients [3] The main manifestations of MCD are systemic symptoms (i.e. high fever, malaise, weight loss), associated with generalised lymphadenopathy and hepatosplenomegaly. The clinical course of MCD in patients with HIV infection is particular because symptoms wax and wane within $24-48 \mathrm{~h}$ at regular intervals, leading authors to use the term "attacks of MCD" $[3,4]$. At the diagnosis of MCD, the degree of immunosuppression of HIVinfected patients is highly variable. Recently, three cases have been reported during the immune reconstitution phase induced by active antiretroviral therapies [5]. Vinblastine or etoposide have been used for MCD treatment $[2,3]$. Monoclonal antibodies (anti-interleukin (IL)-6 receptor, anti-CD20), interferon- $\alpha$, retinoic acid and ganciclovir have been used in several cases [6-10]. Painful splenomegaly or peripheral cytopenia may require splenectomy [3]. Evolution towards lymphoma is frequent and of poor prognosis [11]. Since 1996, MCD associated with HIV infection has been linked with human herpesvirus (HHV)-8 infection. HHV-8 DNA
AFFILIATIONS

Service de *Pneumologie,

${ }^{\S}$ Radiologie, and

${ }^{f}$ Médecine Interne, Hôpital Foch,

Suresnes, and

"Service de Microbiologie, and

+'Immunologie-Hématologie Clinique, Hôpital Saint-Louis, and

\#Service des Maladies Infectieuses et Tropicales, Hôpital Pitié-

Salpétrière, Paris, France.

CORRESPONDENCE

A. Guihot

Service de Pneumologie

Hôpital Foch

40

rue Worth

92151 Suresnes Cedex

France

Fax: 33146252898

E-mail: amelie_guihot@yahoo.fr

Received:

November 142004

Accepted after revision:

March 082005 
sequences have been found in lymph nodes and peripheral blood mononuclear cells (PBMC) of patients suffering from MCD [12]. Moreover, HHV-8 viral load in PBMC increases during MCD attacks [13, 14].

Pulmonary symptoms are reported but under-described in several cases of HIV-associated MCD, and pulmonary infiltrates have been noted during MCD attacks [3, 4]. Thoracic clinical and radiological data have never been previously detailed. Results of fibreoptic bronchoscopy and bronchoalveolar lavage (BAL) are available in a few patients and are mostly normal [4]. The aim of the present study was to analyse the following: 1) clinical and radiological pulmonary features of HIV-associated MCD; 2) BAL results; 3) therapeutic regimens used; and 4) the link between pulmonary manifestations of MCD and HHV-8 infection.

\section{METHODS}

\section{Patients}

Complete clinical files, radiological results and virological data from 12 patients (10 males, two females) suffering from HIVassociated MCD with pulmonary manifestations were analysed retrospectively. Patients came from a prospective cohort of 66 patients followed from January 1990 to September 2003 in three Parisian hospitals for HIV-associated MCD, and were aged 3357 yrs (mean: 44.0 yrs). Five of these patients were previously published without detailing pneumological data $[3,11]$.

Four patients were from Western or Central Africa (patient Nos 5, 8, 10 and 12) and eight patients were Caucasian. Six patients were homosexual males, and six had been HIV infected through heterosexual intercourse. None were intravenous drug users. The previous knowledge of HIV infection dated from 6 months to 16 yrs (mean: 5.4 yrs; range: 5.1). One patient was in an immune reconstitution phase after initiation of antiretroviral therapy (patient No. 7).

The peripheral blood CD4+ cell count ranged 1-340 cells $\cdot \mathrm{mm}^{-3}$ for the nonsplenectomised patients (mean: $253 \mathrm{cells} \cdot \mathrm{mm}^{-3}$; range: 239; table 1). The HIV viral loads ranged from undetectable values to $5.7 \mathrm{log}$ copies $\cdot \mathrm{mm}^{-3}$ (mean: $4.0 \mathrm{log}$ copies $\cdot \mathrm{mm}^{-3}$; range: 2.2 ). All patients were treated with antiretroviral therapy, and nine patients were receiving a protease inhibitor-based highly active antiretroviral therapy for $>3$ months at the time of MCD diagnosis.

Three patients were smokers (patient Nos. 4,6 and 7) and three had previously developed pulmonary infections; pleural tuberculosis (patient Nos 5 and 7) and invasive pulmonary aspergillosis (patient No. 6). Four other patients had had previous nonpulmonary AIDS-related infections (salmonellosis, cytomegalovirus retinitis, isosporiasis and Mycobacterium avium infection in patient Nos 2, 4, 8 and 12, respectively). Seven patients had cutaneous Kaposi's sarcoma (patient Nos 1, $3,6,8,9,10$ and 12), and one patient had undergone splenectomy for immune thrombocytopenia (patient No. 6).

\section{Histopathology}

The diagnosis of MCD was established according to Keller's classification on peripheral lymph-node biopsy analysis in all patients [2]. Three patients exhibited plasma-cell type MCD and nine showed a mixed type. No aspects of Kaposi's sarcoma or HIV-related lymphoid hyperplasia were observed.

\section{Radiology}

Chest radiograph and computed tomography (CT) scans were reviewed by A. Scherrer without knowledge of the patient's files.

\section{Fibreoptic bronchoscopy and BAL}

Fibreoptic bronchoscopy was performed after topical lidocaine anaesthesia. BAL was performed on a segmental bronchus of a radiologically impaired lung territory. A minimum of $100 \mathrm{~mL}$ and a maximum of $200 \mathrm{~mL}$ of $0.9 \%$ saline solution was instilled through the bronchoscope and recovered by soft manual syringe suction. Samples of pooled lavage fluid were analysed for bacterial, mycobacterial, cytological, fungal and virological studies. Specific silver stains for Pneumocystis carinii were performed.

\section{TABLE 1 Patients' characteristics at diagnosis}

\begin{tabular}{|c|c|c|c|c|c|c|c|c|c|}
\hline $\begin{array}{l}\text { Patient } \\
\text { No. }\end{array}$ & $\begin{array}{l}\text { Age } \\
\text { yrs }\end{array}$ & Sex & $\begin{array}{l}\text { CD4 cell } \\
\text { count } \mathrm{mm}^{-3}\end{array}$ & $\begin{array}{l}\text { HIV plasmatic } \\
\text { VL log } \mathrm{cp} \cdot \mathrm{mL}^{-1}\end{array}$ & $\begin{array}{l}\text { Cough/ } \\
\text { sputum }\end{array}$ & $\begin{array}{l}\text { Dyspnoea/ } \\
\text { crackles }\end{array}$ & $\begin{array}{c}\mathrm{Pa}, \mathrm{O}_{2} \\
\mathrm{kPa}\end{array}$ & $\begin{array}{c}\mathrm{Pa}_{1} \mathrm{CO}_{2} \\
\mathrm{kPa}\end{array}$ & $\begin{array}{l}\text { HHV-8 VL min.-max. } \\
\text { cp. } 150,000^{-1} \text { PBMC }\end{array}$ \\
\hline 1 & 51 & M & 50 & 5.7 & $+/-$ & $+/+$ & 8.91 & 4.39 & $<50-5,261,194$ \\
\hline 2 & 49 & M & 150 & ND & $+/+$ & $-/-$ & 8.64 & 5.05 & $606-703,425$ \\
\hline 3 & 36 & M & 340 & 4.3 & $+/+$ & $+/+$ & 8.77 & 4.52 & $<75-4,169,765$ \\
\hline 4 & 54 & M & 133 & ND & $-/-$ & $+/+$ & 7.58 & 2.79 & $550-11,737$ \\
\hline 5 & 41 & M & 226 & $<20$ & $+/-$ & $+/+$ & 9.57 & 4.39 & 1,275 \\
\hline 6 & 46 & M & 875 & 1 & $+/-$ & $+/+$ & ND & ND & $11,233-409,500$ \\
\hline 7 & 46 & M & 140 & 1.9 & $+/-$ & $+/+$ & 10.64 & 3.99 & $<75-2,075,600$ \\
\hline 8 & 33 & $\mathrm{~F}$ & 198 & 5.1 & $+/+$ & $+/+$ & 94 & 5.32 & 2,883-905,900 \\
\hline 9 & 57 & M & 171 & 5 & $-/-$ & $-/+$ & 10.77 & 4.52 & $<50-332,800$ \\
\hline 10 & 36 & $\mathrm{~F}$ & 10 & 6.1 & $+/-$ & $+/-$ & 6.12 & 4.52 & $23,041-25,683$ \\
\hline 11 & 39 & M & 167 & $<50$ & $+/+$ & $-1+$ & 12.64 & 4.25 & $302-2,997$ \\
\hline 12 & 40 & M & 1 & 3.9 & $+/-$ & $+/+$ & 10.77 & 3.32 & $<75-375$ \\
\hline
\end{tabular}

VL: viral load; $\mathrm{cp}$ : copies: $\mathrm{Pa} \mathrm{O}_{2}$ : arterial oxygen tension; $\mathrm{Pa}_{1} \mathrm{CO}_{2}$ : carbon dioxide arterial tension; HHV: human herpesvirus; min.: minimum; max.: maximum; PBMC: peripheral blood mononuclear cells; M: males; F: females; ND: not done; +: present; -: absent. 


\section{HHV-8 and HIV virological studies}

HIV viral load analysis was performed using the ChironQuantiplex® HIV-1 RNA 3.0 technique, as described elsewhere [15]. HHV-8 quantitative viral load evaluation in PBMC and BAL fluid was performed as previously described [14]. The serological HHV-8 tests performed with immunofluorescence assay detected antibodies to latency-associated nuclear antigens.

\section{RESULTS}

\section{Pulmonary manifestations}

Pulmonary symptoms occurred at the first MCD attack in 10 patients. In two cases (patient Nos 2 and 8), pulmonary manifestations appeared during the second and fourth MCD attack. For all patients, pulmonary symptoms developed simultaneously with severe systemic manifestations: highgrade fever, malaise, generalised lymphadenopathy and hepatosplenomegaly. All patients presented a rapid onset of respiratory symptoms within 24-72 h. Patients exhibited dyspnoea $(n=9)$, cough $(n=10)$ and expectoration $(n=4)$, without haemoptysis (table 1 ). All patients were highly febrile $\left(>38^{\circ} \mathrm{C}\right)$. On physical examination, bilateral inspiratory crackles were discernable in 10 patients. Arterial blood gas analysis while breathing at room air showed hypoxaemia (arterial oxygen tension $<11.30 \mathrm{kPa}$ ) in nine cases, with hypocapnia (carbon dioxide arterial tension $<5.05 \mathrm{kPa}$ ) in nine cases. Two patients (patient Nos 4 and 12) presented with adult respiratory distress syndrome and were admitted to an intensive care unit.

Chest radiographs showed bilateral diffuse infiltrates with an interstitial and acinar pattern in all patients, with enlargement of the mediastinum suggesting mediastinal lymphadenopathy in five cases. Three patients exhibited mild bilateral pleuritis, accompanying interstitial infiltrates (fig. 1a). Thoracic CT scans performed in nine patients showed diffuse bilateral interstitial pneumonia with bronchovascular thickening $(n=6)$, septal thickening $(n=7)$ and subpleural nodules ( $n=7$; table 2; fig. 2). A CT scan in one patient (patient No. 11) showed ground-glass attenuation images. No pulmonary consolidation, bronchial dilatation or cysts were seen. Mediastinal lymph nodes were present in eight cases (main diameter: 10-30 mm). Three patients exhibited bilateral pleural effusion.

All patients underwent fibreoptic bronchoscopy. The fibreoptic bronchoscopies were visually normal, without Kaposi's sarcoma lesions. BAL was performed in 11 patients (table 2). Fluid analysis revealed alveolar hypercellularity $(>200,000$ cells $\left.\cdot \mathrm{mL}^{-1}\right)$ in five cases and alveolar lymphocytosis $(>50,000$ lymphocytes $\left.\cdot \mathrm{mL}^{-1}\right)$ in seven cases. Perl's colouration disclosed $>20 \%$ siderophage in two cases. Specific stains and cultures for bacteria, mycobacteria, fungi and viruses were negative.

One patient (patient No. 12) underwent a bronchial biopsy, which showed normal bronchial tissue without lymphoid or plasma cell infiltration.

In one case (patient 8), pleural fluid analysis showed a nonhaemorrhagic transsudate (protein level: $24 \mathrm{~g} \cdot \mathrm{L}^{-1}$ ) with 130 cells $\cdot \mathrm{mm}^{-3}$, mainly made up of macrophages. Cytological examination showed large nonmalignant lymphoid cells without monoclonality detected by immunohistochemical analysis.
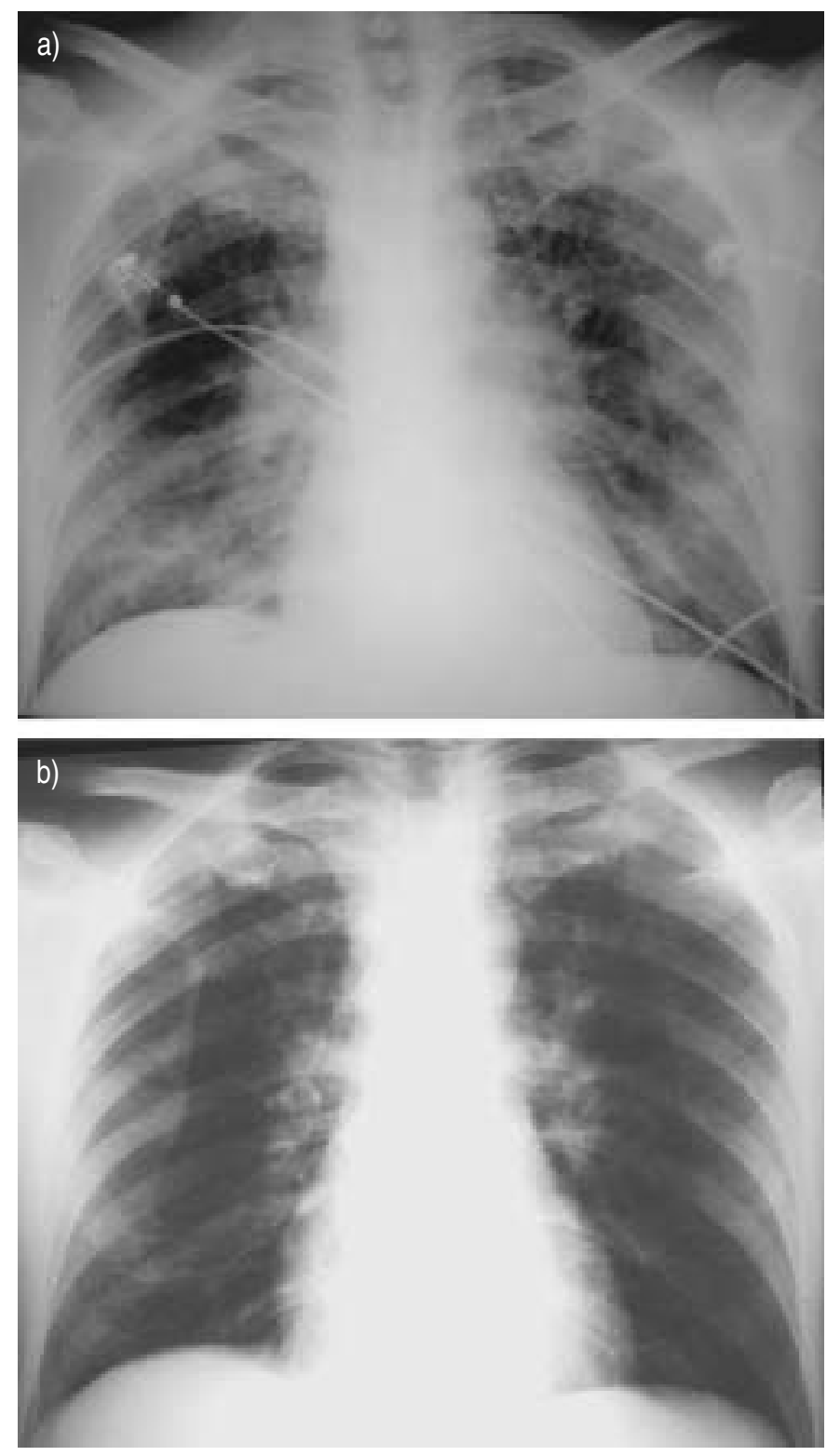

FIGURE 1. Chest radiograph from patient No. 11 showing a) mediastinal enlargement and interstitial infiltrates during multicentric Castleman's disease exacerbation with fever, splenomegaly and generalised lymphadenopathy, and b) infiltrate improvement 8 days later after chemotherapy treatment.

\section{Extrapulmonary symptoms}

All patients exhibited peripheral lymphadenopathy, associated with hepatomegaly in 10 cases, and with splenomegaly in 10 cases. These symptoms wax and wane with similar features at each MCD attack, lasting 5-15 days.

One patient (patient No.9) developed haemophagocytic syndrome at each MCD attack. The diagnosis was made based on severe anaemia, very high serum ferritin levels and increased serum triglycerides levels.

\section{HHV-8 analysis}

HHV-8 serology tests were positive for all but one patient (patient No. 5). HHV-8 DNA sequences were detected in PBMC in all 12 cases (table 1). HHV-8 DNA viral load ranged 
TABLE 2 Thoracic computed tomography (CT) scan findings and bronchoalveolar lavage (BAL) results

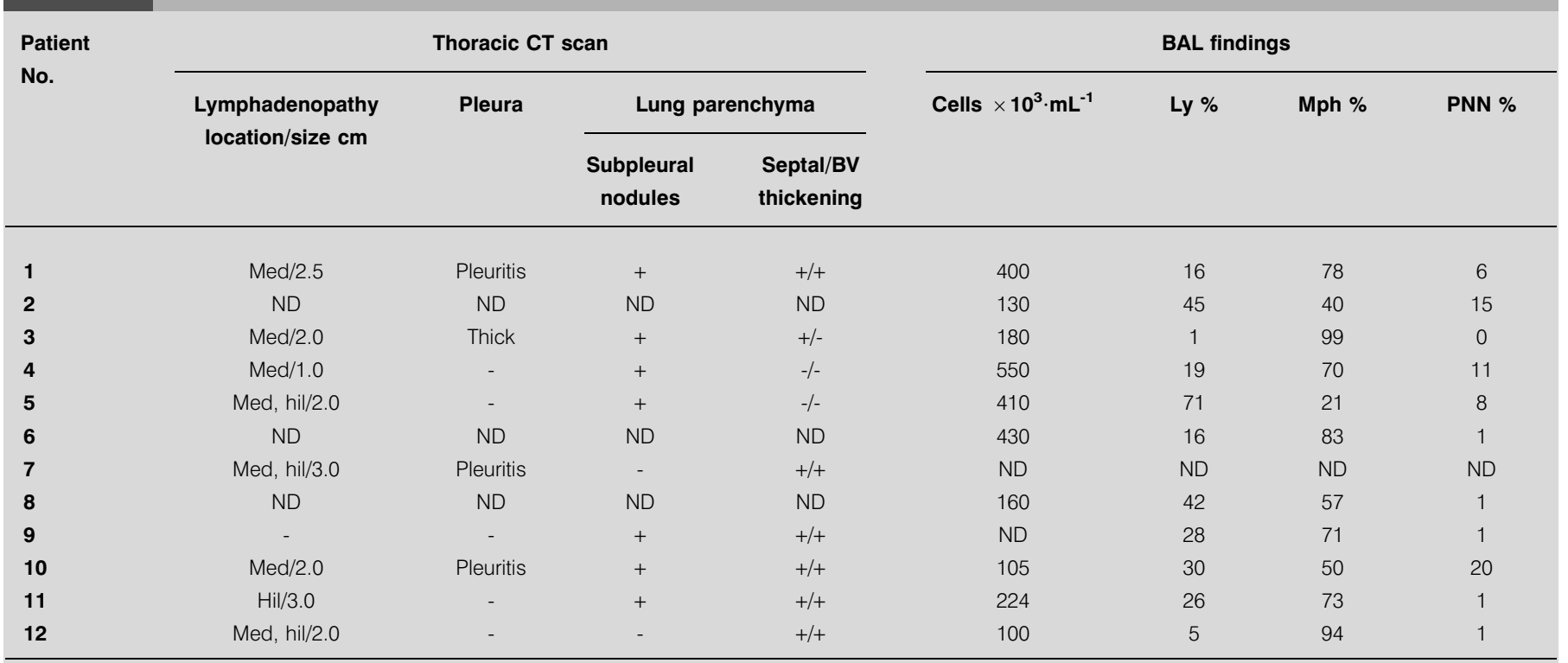

BV: bronchovascular; Ly: lymphocytes; Mph: macrophages; PNN: polynuclear neutrophils; med: mediastinal; hil: hilar; thick: thickening; ND: not done; +: present; -: absent.

from undetectable values to 5,261,194 copies $\cdot 150,000 \mathrm{PBMC}^{-1}$. The highest viral loads were observed during MCD attacks, as illustrated by data from patient No. 1 (fig. 3). HHV-8 DNA copies were searched for and detected in the BAL fluid of two out of 12 patients (patient Nos 1 and 6; 38,224 and 124 copies $\cdot 150,000$ cells $^{-1}$, respectively). These viral loads were lower than those obsereved in PBMC.

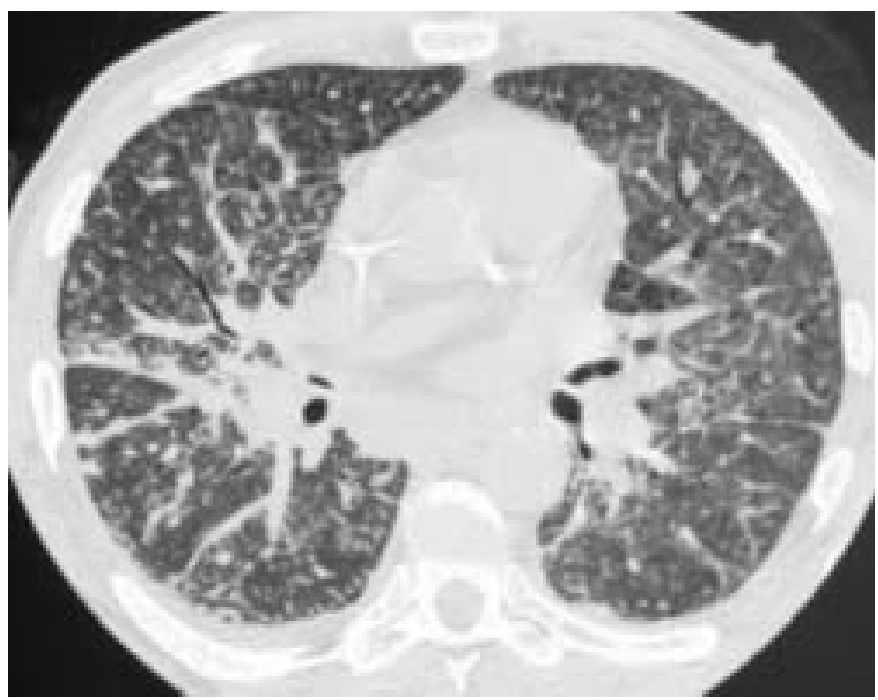

FIGURE 2. Thoracic chest computed tomography scan from patient No. 1 showing interstitial pneumonitis with centrilobular nodules, peribronchovascular thickening, septal thickening and subpleural nodules during multicentric Castleman's disease attack with fever, peripheral lymphadenopathy, dyspnoea and bilateral crackles. Arterial gas analysis results revealed an arterial oxygen tension of $6.91 \mathrm{kPa}$ and an arterial carbon dioxide tension of $4.65 \mathrm{kPa}$.

\section{Follow-up and therapy}

Clinical course of MCD

The mean follow-up period from MCD diagnosis was 41 months (extremes: 4-108 months; table 3). First-line treatment consisted of a single chemotherapeutic agent. This was either etoposide, vinblastine or cyclophosphamide (11 patients), with high-dose i.v. methylprednisolone (four patients), or anti-CD20 monoclonal antibody (one patient). Relapses were frequent (50 MCD attacks in 12 patients), occurring at intervals ranging from 3 weeks to 64 months. Second-line treatment consisted of

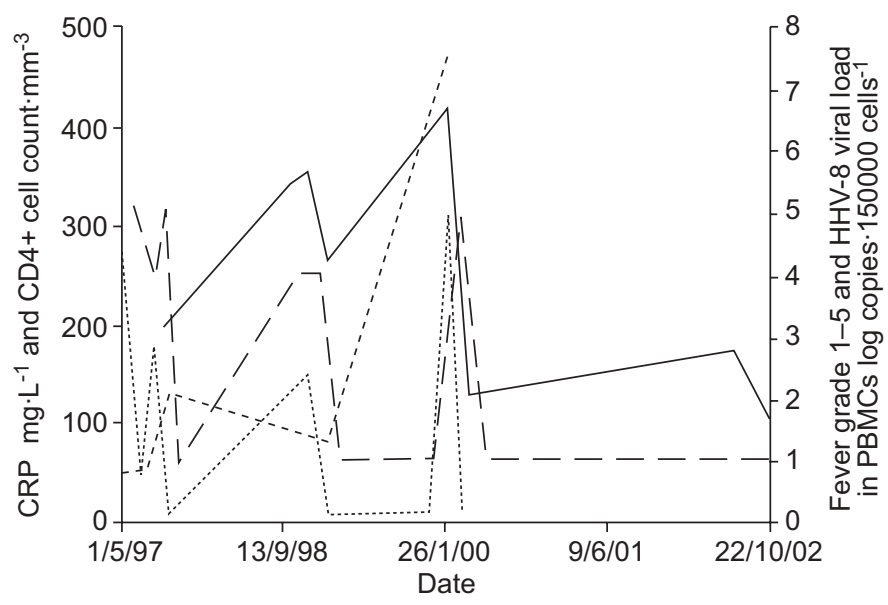

FIGURE 3. Evolution of fever (----), C-reactive protein (CRP) plasmatic level

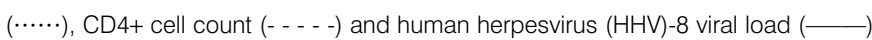
in peripheral blood mononuclear cells (PBMCs) in patient No. 1. Clinical HIVassociated multicentric Castleman's disease attacks, represented by fever, correspond to high CRP plasmatic levels and high HHV-8 viral loads in PBMCs. Immune reconstitution was correct with HIV antiretroviral therapy. 


\begin{tabular}{|c|c|c|c|c|c|c|c|}
\hline $\begin{array}{l}\text { Patient } \\
\text { No. }\end{array}$ & $\begin{array}{l}\text { First-line } \\
\text { regimen }\end{array}$ & $\begin{array}{l}\text { Second-line } \\
\text { regimen }\end{array}$ & $\begin{array}{l}\text { Definitive } \\
\text { regimen }\end{array}$ & $\begin{array}{c}\text { Follow-up } \\
\text { months }\end{array}$ & Outcome & $\begin{array}{c}\text { Last } \\
\mathrm{CD} 4 \cdot \mathrm{mm}^{-3}\end{array}$ & $\begin{array}{l}\text { HIV VL } \\
\text { cp } \cdot \mathrm{mL}^{-1}\end{array}$ \\
\hline 1 & $\mathrm{MP} / \mathrm{Cycl} / \mathrm{Vlb}\left(1^{\#}\right)$ & VP16/Doxo/Cycl $\left(3^{\#}\right) / S p l$ & VP16/3 w & 65 & $\mathrm{CR}$ & 471 & Und. \\
\hline 2 & $\mathrm{VIb}\left(3^{\#}\right)$ & Spl & $\mathrm{Vlb} / 3 \mathrm{w}$ & 30 & $\mathrm{D}(\mathrm{NHL})$ & 595 & 4.1 \\
\hline 3 & $\mathrm{VIb}\left(49^{\#}\right)$ & Spl & VP16/3 w & 63 & $\mathrm{D}(\mathrm{NHL})$ & 789 & Und. \\
\hline 5 & VP16 & & VP16/2 m & 18 & $\mathrm{CR}$ & 504 & Und. \\
\hline 6 & MP/Cycl (2\#) & $\operatorname{VIb}\left(11^{\#}\right)$ & VP16/3 w & 84 & $\mathrm{D}(\mathrm{NHL})$ & 947 & Und. \\
\hline 7 & VP16 & & VP16/2 w & 15 & PEL-CR & 114 & Und. \\
\hline 8 & MPNP16 $\left(1^{\#}\right)$ & Spl & VP16/2 w & 17 & $\mathrm{CR}$ & 1002 & Und. \\
\hline 9 & Vlb $\left(12^{\#}\right) / \mathrm{Spl}$ & VP16 & VP16/2 m & 62 & $\mathrm{D}(\mathrm{PEL})$ & 975 & Und. \\
\hline 10 & VP16 $\left(2^{\#}\right)$ & & & 18 & PEL-CR & ND & ND \\
\hline
\end{tabular}

VL: viral load; cp: copies; MP: methylprednisolone; Cycl: cyclophosphamide; Vlb: vinblastine; Spl: splenectomy; VP16: etoposide; Ab: antibody; Doxo: doxorubicin; w: weeks; m: months; CR: complete response wtih treatment; D: death; NHL: non-Hodgkin's lymphoma; PEL: primary effusion lymphoma; und.: undetectable: ND: not done. \#: number of chemotherapy cycles administered.

etoposide (administrated for 17 attacks), vinblastine $(n=12)$, steroids $(n=2)$, cyclophosphamide $(n=3)$, doxorubicin $(n=3)$ and anti-CD20 monoclonal antibody $(n=4)$.

During the $50 \mathrm{MCD}$ attacks patients exhibited the following: fever (all 50 cases); peripheral lymphadenopathy (45 cases); interstitial infiltrates (36 cases); mediastinal widening (18 cases); and bilateral pleuritis (11 cases). Fever, malaise, peripheral lymphadenopathy, pulmonary symptoms, chest radiograph infiltrates and mediastinal widening settled within $24 \mathrm{~h}$ to 10 days in all patients (fig. 1b).

It is noteworthy that, in 17 attacks, systemic manifestations and pulmonary symptoms disappeared spontaneously without cytotoxic chemotherapy or steroids. In these cases, clinical attacks lasted a little longer (3-10 days) compared with patients receiving treatment.

\section{Splenectomy}

Six patients underwent splenectomy for cytopenia (five cases) and/or painfulness (two cases). Histological examination of the spleen showed MCD lesions in four cases, diffuse plasma cell infiltration in one and nonspecific fibrotic lesions in the last case. Neither lymphoma nor infectious disease was suggested.

\section{Haemophagocytic syndrome}

Five years after MCD diagnosis, patient No. 5 developed haemophagocytic syndrome concurrently with an MCD attack. Haemophagocytic syndrome was proven by bone-marrow analysis.

\section{Development of malignancies}

Six patients developed non-Hodgkin's lymphoma: primary effusion lymphoma (three cases with pleural effusion in patient Nos 7 and 9, and polyserositis in patient No. 10, in which HHV-8 viral load was $>9.10^{6}$ copies $\cdot 150,000$ cells $^{-1}$ ), medullary plasmablastic lymphoma (patient Nos 2 and 3) and cardiac large B-cell lymphoma (patient No. 6). No patient developed pulmonary lymphomatous involvement. The patients were treated with cytotoxic chemotherapy regimen (cyclophosphamide, doxorubicin, vincristine and prednisone in patient Nos 6, 7, 9 and 10), anti-CD20 monoclonal antibodies(patient No. 2), and cyclophosphamide/doxorubicin regimen (patient No. 3). Four patients died of lymphoma progression. Kaposi's sarcoma developed in three patients following the diagnosis of MCD (patient Nos 2, 4 and 7), with cutaneous involvement in two cases and pericardial extension in one. The clinical course of Kaposi's sarcoma was not correlated with MCD exacerbations or lymphoma occurrence. It is noteworthy that including the patients with previously diagnosed Kaposi's sarcoma, eight out of 12 patients suffered from Kaposi's sarcoma at the end of follow-up.

\section{HIV infection}

All patients were treated with highly active antiretroviral therapy. Nine patients had undetectable plasma HIV viral load at the end of follow-up. The most recent mean CD4+ cell count was 554 cells $\cdot \mathrm{mm}^{-3}$ (extremes: 24-1002; table 3). Six patients had undergone splenectomy. Only one patient (patient No. 4) developed an opportunistic infection (cytomegalovirus retinitis) 5 yrs later. Patient No. 2 had high HIV viral load $\left(\sim 5 \log\right.$ copies $\left.\cdot \mathrm{mm}^{-3}\right)$, while the post-splenectomy CD4+ cell count remained $\sim 700 \cdot \mathrm{mm}^{-3}$ because the patient did not comply with the treatment. The patient did not develop opportunistic infections. The CD4+ cell number failed to rise in spite of highly active antiretroviral therapy in patient No. 12.

\section{Survival}

Five out of 12 patients died during the 41-month follow-up period (fig. 4). Four patients died from lymphoma progression after a short mean survival time (2.5 months), in spite of chemotherapy. Two of them died from a medullary plasmablastic lymphoma, one from primary effusion lymphoma and one from cardiac large B-cell lymphoma. Patient No. 12 died from a bacterial sepsis in spite of antibiotics and the best supportive care. 


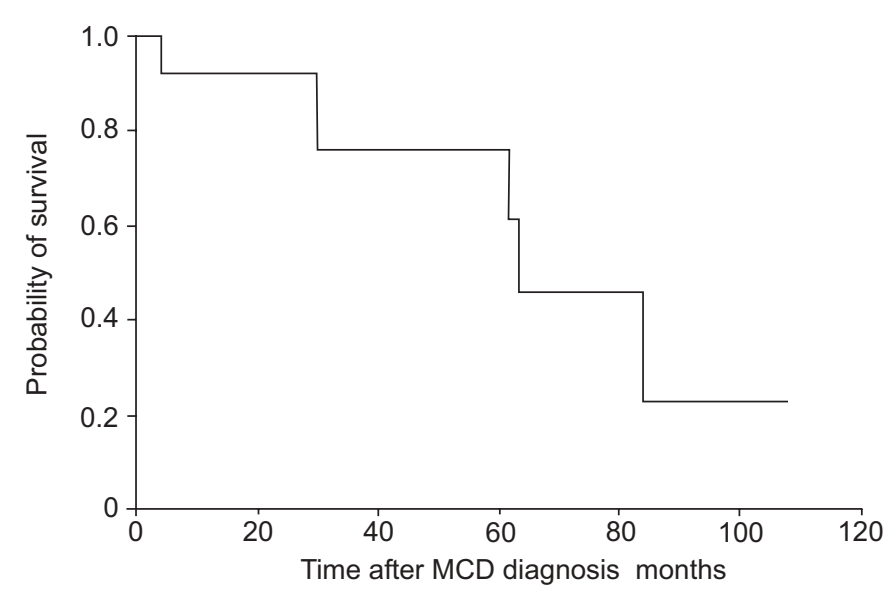

FIGURE 4. Kaplan-Meier probability of survival in 12 patients with pulmonary manifestations of HIV-related multicentric Castleman's disease (MCD).

\section{DISCUSSION}

In total, $12 \mathrm{HIV}$-infected patients with pulmonary manifestations of MCD were enrolled out of a cohort of 66 patients with HIV-associated MCD. The most frequent pulmonary manifestation was an acute febrile interstitial pneumonitis, which: 1) occurs simultaneously to systemic complaints (high fever, weight loss and malaise); 2) waxes and wanes in a short time; and 3 ) is associated with high levels of HHV-8 DNA in peripheral blood and BAL fluid when performed during attacks. The clinical course is particular due to a high incidence of non-Hodgkin's lymphoma (six out of 12 patients) and a high mortality rate (five deaths in 12 patients).

\section{Previous reported cases of HIV-associated MCD}

It has been previously reported that HIV-infected patients suffering from MCD complained of dyspnoea with radiological infiltrates $[3,4,16]$. In one of these reports, five patients underwent fibreoptic bronchoscopy, which was normal in all cases. BAL fluid cytology was reported to be normal, and HHV-8 DNA was found in one patient. No radiological data were available [4]. Interstitial pneumonitis has been reported as a pulmonary feature of MCD in 12 patients [17]. However, no clinical data or HIV serological status were available in this study. In these patients, lymphoid interstitial pneumonitis was histologically diagnosed with open lung biopsy or transbronchial lung biopsy in seven out of 12 cases.

\section{MCD in non-HIV-infected patients}

The interstitial pneumonitis observed in the patients clearly differs from the usual thoracic manifestations of HIV-negative patients with MCD. The latter form presents with diffuse and large lymphadenopathy involving multiple mediastinal compartments, rarely with reticulo-nodular opacities on chest radiographs [18-20].

\section{Differential diagnosis}

The pneumonitis described in the patients is very likely to be due to MCD, because it developed simultaneously with the systemic symptoms of MCD in all patients. However, as no histological lung samples have been analysed in the present study, lymphoid interstitial pneumonitis may be suggested as a cause of interstitial pneumonitis. This hypothesis may be ruled out because lymphoid interstitial pneumonitis in HIVinfected patients is a very slow, progressive and nonfebrile disease, which sharply contrasts with the acute interstitial pneumonitis seen in the patients [21].

In HIV-infected patients, most acute interstitial pneumonitis is of infectious origin, mainly $P$. carinii pneumonia. Here, the current authors have excluded this diagnosis with BAL, which is almost $100 \%$ sensitive to the diagnosis of $P$. carinii pneumonia in HIV-infected patients [22]. Another argument against infectious pneumonitis in the current patients is given by the clinical course, as no patient developed infectious pneumonia during the follow-up period without specific antiinfectious treatment.

A haemophagocytic syndrome occurred in two patients: one at each MCD attack, and one after a 5-yr evolution of MCD. A recent study described three cases of haemophagocytic syndrome during MCD attacks with respiratory distress syndrome [16]. These pulmonary manifestations are not specifically related to MCD because they may occur during haemophagocytic syndrome in HIV-infected patients without MCD [23].

Evolution towards a non-Hodgkin's lymphoma was a frequent finding in the current patients, occurring in six out of 12 cases (including three primary effusion lymphomas, which have been related to HHV-8 infection [24]). Occurrence of an HHV8 -associated lymphoma is a well-known complication of MCD during HIV infection, which occurs in $\sim 25 \%$ of cases $[3,11]$. A trigger role of HHV-8 in a lymphoproliferation outcome has been evoked [25]. In the present study, no patient developed pulmonary non-Hodgkin's lymphoma involvement, excluding that the observed interstitial pneumonitis could reflect a pulmonary pre-lymphomatous state.

\section{Pathophysiology}

The pathophysiology of pulmonary manifestations during HIV-associated MCD may rely on immunovirological facts. HHV-8, as a member of the herpesvirus family, has two modes of replication in infected cells: lytic and latent. HHV-8 latently infects CD19+ B-cells, endothelial cells, fibroblasts and macrophages [26, 27]. A HHV-8 tropism for lung tissues has been described in chronic plexiform lesions of primary pulmonary hypertension of non-HIV-infected patients [28], and in HIVrelated recurrent pleural effusion [29]. It has been shown that HHV-8 reactivates in peripheral blood during MCD exacerbations without pulmonary involvement [13], and the current authors report similar data. During $\mathrm{HIV}$ and $\mathrm{HHV}-8$ coinfection, cells found in interstitial lung compartments (i.e. fibroblasts, endothelial cells, macrophages), may be, like CD19+ B peripheral cells [25], chronically infected by HHV-8. HHV-8 reactivation in these cells (i.e. lytic replication) during MCD exacerbations could result in interstitial compartment inflammation. The same reactivation in pulmonary vascular endothelium could alter the endothelial barrier and result in vascular leakage. Additionally, a possible role of cytokines may be provided. There is a systemic overproduction of pro-inflammatory cytokines, such as IL-6 and IL-10, during MCD exacerbations [14]. Furthermore, HHV-8 encodes several human cytokine homologues, such as IL-6, cyclin D and macrophage inflammatory protein-1 [30]. Such an overproduction of 
cytokines may lead to a nonspecific capillary-leak syndrome, as has been studied in critically ill patients [31].

\section{Treatment}

The mainstay in the treatment of HIV-associated MCD is chemotherapy. Vinblastine and etoposide administered alone are used most frequently. Anti-CD20 monoclonal antibody is currently being evaluated. In the present study, etoposide seemed to be the most effective treatment as it has been used in 17 MCD attacks, with the disappearance of symptoms in a few days in 16 cases. After MCD attacks, seven patients received sequential treatment with etoposide. Etoposide prevented MCD attacks in all cases and etoposide could be withdrawn in three cases without MCD relapse. With regards to these data, it seems reasonable to recommend etoposide in acute and chronic treatment of HIV-associated MCD with pulmonary symptoms.

\section{Survival}

Five out of 12 patients died during the follow-up period. This mortality rate is better than that observed in HIV-infected patients with MCD diagnosed before highly active antiretroviral therapies [3], and is equivalent to those observed in small series published more recently $[4,8]$. The small number of published cases does not link survival of MCD patients with the occurrence of pulmonary manifestations.

\section{Conclusion}

To the present authors' knowledge, this is the first study to report 12 cases of HIV-associated MCD with pulmonary manifestations. The main pulmonary impairment is a rapidly progressive interstitial pneumonitis, which concurs with extrapulmonary MCD symptoms, i.e. fever, malaise, peripheral lymphadenopathy and hepatosplenomegaly. An acute respiratory distress syndrome can occur. Severe diffuse patterns can be seen on chest CT scans, and BAL fluid cellularity may be normal. These unspecific data do not assert a diagnosis. However, these MCD "attacks" are associated with an increased HHV-8 viral load in peripheral load and BAL. Symptoms dramatically decrease after cytotoxic chemotherapy. Etoposide seems to be the most effective therapeutic agent, although no guidelines for MCD treatment have been established up to now. Systemic and pulmonary symptoms can also disappear more slowly without treatment. The prognosis is poor, however, because of a high frequency of evolution towards an aggressive non-Hodgkin's lymphoma.

In conclusion, clinicians should be aware that interstitial pneumonitis in HIV-infected patients with multicentric Castleman's disease may be of noninfectious origin. The present authors suggest that bronchoalveolar lavage should be performed in order to exclude opportunistic infections. Similar recurrent episodes with high-grade fever, malaise, peripheral lymphadenopathy and hepatosplenomegaly in patients with previously known multicentric Castleman's disease may allow clinicians to initiate chemotherapy without delay.

\section{REFERENCES}

1 Castleman B, Iverson L, Menendez VP. Localized mediastinal lymphnode hyperplasia resembling thymoma. Cancer 1956; 9: 822-830.
2 Keller AR, Hochholzer L, Castleman B. Hyaline-vascular and plasma-cell types of giant lymph node hyperplasia of the mediastinum and other locations. Cancer 1972; 29: 670-683.

3 Oksenhendler E, Duarte M, Soulier J, et al. Multicentric Castleman's disease in HIV infection: a clinical and pathological study of 20 patients. AIDS 1996; 10: 61-67.

4 Aaron L, Lidove O, Yousry C, Roudiere L, Dupont B, Viard JP. Human herpesvirus 8-positive Castleman disease in human immunodeficiency virus-infected patients: the impact of highly active antiretroviral therapy. Clin Infect Dis 2002; 35: 880-882.

5 Zietz C, Bogner JR, Goebel FD, Lohrs U. An unusual cluster of cases of Castleman's disease during highly active antiretroviral therapy for AIDS. N Engl J Med 1999; 340: 1923-1924.

6 Rieu P, Droz D, Gessain A, Grunfeld JP, Hermine O. Retinoic acid for treatment of multicentric Castleman's disease. Lancet 1999; 354: 1262-1263.

7 Kumari P, Schechter GP, Saini N, Benator DA. Successful treatment of human immunodeficiency virus-related Castleman's disease with interferon-alpha. Clin Infect Dis 2000; 31: 602-604.

8 Marcelin AG, Aaron L, Mateus C, et al. Rituximab therapy for HIV-associated Castleman disease. Blood 2003; 102: 2786-2788.

9 Nishimoto N, Sasai M, Shima Y, et al. Improvement in Castleman's disease by humanized anti-interleukin-6 receptor antibody therapy. Blood 2000; 95: 56-61.

10 Casper C, Nichols WG, Huang ML, Corey L, Wald A. Remission of HHV-8 and HIV-associated multicentric Castleman disease with ganciclovir treatment. Blood 2004; 103: 1632-1634.

11 Oksenhendler E, Boulanger E, Galicier L, et al. High incidence of Kaposi sarcoma-associated herpesvirusrelated non-Hodgkin lymphoma in patients with HIV infection and multicentric Castleman disease. Blood 2002; 99: 2331-2336.

12 Soulier J, Grollet L, Oksenhendler E, et al. Kaposi's sarcoma-associated herpesvirus-like DNA sequences in multicentric Castleman's disease. Blood 1995; 86: 12761280.

13 Grandadam M, Dupin N, Calvez V, et al. Exacerbations of clinical symptoms in human immunodeficiency virus type 1-infected patients with multicentric Castleman's disease are associated with a high increase in Kaposi's sarcoma herpesvirus DNA load in peripheral blood mononuclear cells. J Infect Dis 1997; 175: 1198-1201.

14 Oksenhendler E, Carcelain G, Aoki Y, et al. High levels of human herpesvirus 8 viral load, human interleukin-6, interleukin-10, and C reactive protein correlate with exacerbation of multicentric castleman disease in HIVinfected patients. Blood 2000; 96: 2069-2073.

15 Collins ML, Irvine B, Tyner D, et al. A branched DNA signal amplification assay for quantification of nucleic acid targets below 100 molecules/mL. Nucleic Acids Res 1997; 25: 2979-2984.

16 Fardet L, Blum L, Kerob D, et al. Human herpesvirus 8associated hemophagocytic lymphohistiocytosis in human immunodeficiency virus-infected patients. Clin Infect Dis 2003; 37: 285-291. 
17 Johkoh $\mathrm{T}$, Muller NL, Ichikado $\mathrm{K}$, et al. Intrathoracic multicentric Castleman disease: CT findings in 12 patients. Radiology 1998; 209: 477-481.

18 Barrie JR, English JC, Muller N. Castleman's disease of the lung: radiographic, high-resolution $\mathrm{CT}$, and pathologic findings. AJR Am J Roentgenol 1996; 166: 1055-1056.

19 Kirsch CF, Webb EM, Webb WR. Multicentric Castleman's disease and POEMS syndrome: CT findings. J Thorac Imaging 1997; 12: 75-77.

20 McAdams HP, Rosado-de-Christenson M, Fishback NF, Templeton PA. Castleman disease of the thorax: radiologic features with clinical and histopathologic correlation. Radiology 1998; 209: 221-228.

21 Solal-Celigny P, Couderc LJ, Herman D, et al. Lymphoid interstitial pneumonitis in acquired immunodeficiency syndrome-related complex. Am Rev Respir Dis 1985; 131: 956-960.

22 Hopewell PC. Pneumocystis carinii pneumonia: diagnosis. J Infect Dis 1988; 157: 1115-1119.

23 Bourquelot $\mathrm{P}$, Oksenhendler E, Wolff M, et al. Hemophagocytic syndrome in HIV infection. Presse Med 1993; 22: 1217-1220.

24 Cesarman E, Chang Y, Moore PS, Said JW, Knowles DM. Kaposi's sarcoma-associated herpesvirus-like DNA sequences in AIDS-related body-cavity-based lymphomas. N Engl J Med 1995; 332: 1186-1191.
25 Du MQ, Liu H, Diss TC, et al. Kaposi sarcoma-associated herpesvirus infects monotypic (IgM lambda) but polyclonal naive B cells in Castleman disease and associated lymphoproliferative disorders. Blood 2001; 97: 2130-2136.

26 Staskus KA, Sun R, Miller G, et al. Cellular tropism and viral interleukin-6 expression distinguish human herpesvirus 8 involvement in Kaposi's sarcoma, primary effusion lymphoma, and multicentric Castleman's disease. J Virol 1999; 73: 4181-4187.

27 Blackbourn DJ, Lennette E, Klencke B, et al. The restricted cellular host range of human herpesvirus 8. AIDS 2000; 14: 1123-1133.

28 Cool CD, Rai PR, Yeager ME, et al. Expression of human herpesvirus 8 in primary pulmonary hypertension. $N$ Engl J Med 2003; 349: 1113-1122.

29 Bryant-Greenwood P, Sorbara L, Filie AC, et al. Infection of mesothelial cells with human herpes virus 8 in human immunodeficiency virus-infected patients with Kaposi's sarcoma, Castleman's disease, and recurrent pleural effusions. Mod Pathol 2003; 16: 145-153.

30 Nicholas J, Ruvolo VR, Burns WH, et al. Kaposi's sarcomaassociated human herpesvirus- 8 encodes homologues of macrophage inflammatory protein-1 and interleukin-6. Nat Med 1997; 3: 287-292.

31 Fishel RS, Are C, Barbul A. Vessel injury and capillary leak. Crit Care Med 2003; 31: Suppl. 8, S502-S511. 